\title{
REMOVAL OF CHEST DRAINS IN POST CORONARY ARTERY BYPASS GRAFT PATIENTS: DO VARIOUS PHASES OF RESPIRATION MAKE A DIFFERENCE?
}

\author{
Ahmed Anwar Elnory ${ }^{1}$,Hany Hassan Elsayed ${ }^{1}$, Moustafa Gamal ElBarbary ${ }^{1}$, \\ Shaymaa Hassan Salah ${ }^{2}$, Ahmed Elnady Ahmed Abdelall ${ }^{3}$.
}

1Department of Cardiothoracic Surgery $\&{ }^{2}$ Radiology

Department, Faculty of Medicine

- Ain Shams University

${ }^{3}$ Thoracic Surgery Department,

Nasser Institute Hospital for

Research and Treatment Cairo,

Egypt.

Corresponding author

Ahmed Elnady Ahmed Abdelall

Mobile: (+2) 01062884980

E.mail:

ahmed.abdelall@med.asu.edu.eg

Received: $12 / 7 / 2021$

Accepted: 5/8/2021

Online ISSN: 2735-3540

\begin{abstract}
:
Background: Pleural drainage via intercostal tube is widely used in every trauma center, oncology center and tertiary health care providing centers all over the world, hence there are great efforts directed to find out the best way to manage the intercostal tube during and after its insertion. In this study we try to find out the best respiratory phase, If there is any, to remove the intercostal tube.
\end{abstract}

Aim of the Work: To find out the ideal respiratory phase during which tube thoracostomy can be safely removed.

Patients and Methods: (291) patients who underwent coronary artery bypass grafting surgery have been randomized into four groups according to the phase of respiration they were asked to adapt during pleural drain removal. Intervention: patients were asked to adapt one of the following respiratory phases during the removal process; group endinspiratory, group $(P)$ end-expiratory, Valsalva maneuver after full inspiration $(Q)$ or Valsalva maneuver after full expiration $(R)$ group. Preremoval chest $X$-ray and post removal chest $X$-rays were obtained and compared. This study was conducted between December 2019 and November 2020 in cardiac surgery post-operative intensive care unit at Nasser Institute Hospital.

Results: By comparing pre and post removal chest $X$-ray films to detect small insignificant recurrent pneumothorax, which is newly developed pneumothorax or increased existing small pneumothorax, in 6 patients in group $(P), 8$ patients in group $(Q), 7$ patients in group $(R)$ and 5 patients in group $(S)$. Significant pneumothorax occurred in additional 2 cases in group $(R)$ which required re-insertion of intercostal tube.

Conclusion: It is safe to remove chest tube in any phase of respiration if performed by a well-trained physician.

Keywords: Intercostal tube, Tube thoracostomy, Chest tube, Coronary artery bypass graft, pleural drain removal, recurrent pneumothorax, Open heart.

\section{INTRODUCTION:}

The early management of the postoperative open heart surgery patient can be viewed as an extension of the intra operative care the patient received ${ }^{(1)}$, There is a continuous decline in mortality and morbidity in cardiac surgery despite increases in patient age, comorbid conditions, and procedure complexity. Much of this success can be attributed to advances in critical care. In addition to many other aspects special efforts are directed towards circulatory and respiratory stabilization ${ }^{(2)}$, 
and here comes the importance of mediastinal and pleural drains as they must be closely observed to ensure vital stabilization of the patient in addition to monitoring systems, so, it is important to keep them patent ${ }^{(3)}$ and functioning.

It's also important to remove pleural drain in the right time to avoid possible undetected mediastinal bleeding or fluid re-accumulation in open pleura which may result from premature removal. And to avoid infection, prolonged exposure to pain and prolonged mechanical irritation which may result from their prolonged stay ${ }^{(4)}$.

When time comes they must be removed in the right way i.e. in sterile conditions and for pleural drainage, the phase of respiratory cycle needs to be put in consideration. Proper removal is critical to reduce the risk of recurrent pneumothorax. The focus is to prevent air from re-entering the pleural space by minimizing the exposure of the thoracostomy site to the atmosphere ${ }^{(5)}$.

\section{PATIENTS AND METHODS:}

This is a randomized controlled trial study that was conducted in Nasser institute hospital between December 2019 and November 2020

Patients criteria; All patients who had coronary artery bypass graft (CABG) surgery ,either isolated or combined with other valve surgery, from both sexes were included. Exclusion criteria included Patients with severe uncontrolled lung pathology, patients on mechanical ventilation, patients who had extra-pleural left internal mammary artery harvesting, patients who refuse to participate in the study or not fully conscious during the procedure or lack legal eligibility.

Randomization and groups; Randomization was done by successive allocation of patients in the study groups which was divided as following: Group (P) for removal in the end of expiration which contained 72 patients, group (Q) for removal during Valsalva maneuver in inspiration which contained 75 patients, group (R) for removal in Valsalva maneuver in the end of expiration which contained 73 patients and group (S) for removal in the end of inspiration and contained 71 patients.

Sample size; Using STATA program setting alpha error at 5\% and power of study at $90 \%$, results from previous study (Thitivaraporn et al;2017) (3) showed that $0 \%$ of valsalva cases had recurrent pneumothorax compared to $15 \%$ and $17 \%$ in classic inspiration and expiration respectively. Based on this 70 cases per group (total 280) were needed taking in account $20 \%$ dropout rate. but we managed to keep the number above 70 regardless the excluded cases.

Study tools; Pre removal Chest X-ray film, dressing trolley which contained sterile wound dressing kits, suture cutter, disinfectant solution and post removal chest $\mathrm{X}$-ray film.

Study intervention: Multiple sidebores GMS pleural drains of size 32-40 Fr. without trocar were placed intra-operatively and anchored with size 1 silk suture and stay suture with the same thread was also inserted. Drain removal criteria included the following; no air leak in any of the drains, drain must be functioning, minimal drainage ( $<150 \mathrm{~mL} / 24$ Hours) of serous or serosanguineous nature but not bloody and full lung expansion confirmed by pre removal chest X-ray. The required respiratory phase was acquired according to the following: In end-inspiratory group patient was asked to inhale deeply then to hold his/her breath. In end-expiratory group patient was asked to exhale completely and hold his/her breath. In Valsalva expiratory group patient was asked to completely exhale and to strongly strain against closed epiglottis. In Valsalva inspiratory group the patient was asked to 
deeply inhale and then strain (bear down) against closed epiglottis.

Patients' follow up; Patients were followed up by Chest X-Ray after 12- 24 hours taking in consideration the possibility of earlier need of chest X-ray if respiratory compromise occurs but we didn't need it. In cases with significant pneumothorax chest tube was re-inserted. Frequent physiotherapy, high flow Oxygen through nasal cannula and close observation for patients with minimally progressive or new minimal pneuomothorax.

\section{Statistical analysis:}

Data have been collected throughout pre and post pleural drain removal Chest X-ray films, from the medical file of each patient, from clinical examination and from clinical data. The collected data were subjected to statistical analysis using statistical package for social science (IBM SPSS) version 20.0 (Armonk, NY: IBM Corp). For categorial variables we used Chi square test to compare between different groups. For quantitative variables which are normally distributed $\mathrm{We}$ used F-test (ANOVA) to compare between more than two groups. Kruskal Wallis test was used for abnormally distributed variables in comparing more than two groups. normality of distribution was verified using Kolmogorov-Simlov test. We used range (minimum and maximum), mean deviation, standard deviation, median range and interquartile range (IQR) to describe quantitative data. The level of significance was judged by using $p$ value and we considered the results statistically significant when $\mathrm{p}$ value was $<0.05$.

\section{RESULTS:}

Demographic data: The mean age in years and standard deviation at time of study was $60.17 \pm 7.70$ for P group, $57.44 \pm 7.47$ for Q group, 56.92 \pm 7.37 for $\mathrm{R}$ group and 58.25 \pm 7.54 for $\mathrm{S}$ group. Of 72 patients in $\mathrm{P}$ group
65 patients were male and 7 females, of 75 patients in Q group there were 64 males and 11 females, of 73 patients in $\mathrm{R}$ group there were 64 males and 9 females and in $S$ group there were 60 males and 11 females. Statistical analysis of these data showed no statistical significance between the four groups regarding the demographic data as shown in Table (1).

General risk factors; $46.39 \%$ of patients had diabetes mellitus. Their distribution in the four groups ranged from $45.1 \%$ to $48.6 \%$ which was statistically insignificant. $48.45 \%$ of study patients had hypertension. Their distribution in the study groups ranged from $39.4 \%$ to $57.5 \%$ which was statistically insignificant. Regarding hypercholesterolemia we have obtained the data of 287 patients. $10.1 \%$ of them had hypercholesterolemia and their distribution in the study groups ranged from $5.7 \%$ to $13.9 \%$ which showed statistical insignificance upon analysis. Regarding the ejection fraction (EF) obtained from the echocardiography reports of 287 patients, 56 patients had fair cardiac function (EF 30$50 \%$ ) and 231 patients had good cardiac function $(\mathrm{EF}>50 \%)$ and their distribution in the study group showed statistical insignificance as shown in Table (2).

Respiratory risk factors; Regarding the respiratory diseases, data of 287 patients were obtained and 4 of them had a chronic obstructive pulmonary disease (COPD) while the others didn't have a history of either chronic or clinically significant acute respiratory conditions. Statistical analysis of data showed statistical insignificance. Regarding smoking, data of 284 patients were obtained and 142 patients have never smoked, 113 patients were ex-smokers and 29 patients were still smoking. The distribution of smoking data is shown in table (4) \& Diagram (7). Statistical analysis of data showed statistical significance ( $p$ value $=0.025)$ as shown in Table (3). 
Table (1): Demographic factors distribution in the four groups.

\begin{tabular}{|c|c|c|c|c|c|c|c|c|c|c|}
\hline & \multicolumn{2}{|c|}{$\begin{array}{c}\text { S (End } \\
\text { inspiratory) } \\
(\mathrm{n}=71)\end{array}$} & \multicolumn{2}{|c|}{$\begin{array}{l}\mathrm{R} \text { (Valsalva } \\
\text { expiratory) } \\
(\mathrm{n}=73)\end{array}$} & \multicolumn{2}{|c|}{$\begin{array}{l}\mathrm{Q} \text { (Valsalva - } \\
\text { inspiratory) } \\
(\mathrm{n}=75)\end{array}$} & \multicolumn{2}{|c|}{$\begin{array}{c}\mathrm{P}(\text { End- } \\
\text { expiratory) } \\
(\mathrm{n}=72)\end{array}$} & \multirow[t]{2}{*}{$\begin{array}{l}\text { Test } \\
\text { of sig. }\end{array}$} & \multirow[t]{2}{*}{$\mathrm{p}$} \\
\hline & No. & $\%$ & No. & $\%$ & No. & $\%$ & No. & $\%$ & & \\
\hline \multicolumn{11}{|l|}{ Gender } \\
\hline Male & 60 & 84.5 & 64 & 87.7 & 64 & 85.3 & 65 & 90.3 & \multirow{3}{*}{ 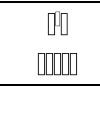 } & \multirow[t]{2}{*}{0.734} \\
\hline Female & 11 & 15.5 & 9 & 12.3 & 11 & 14.7 & 7 & 9.7 & & \\
\hline \multicolumn{10}{|l|}{ Age (years) } & \\
\hline Min. - Max. & \multirow{2}{*}{\multicolumn{2}{|c|}{$\begin{array}{c}38.0-74.0 \\
58.25 \pm 7.54\end{array}$}} & \multicolumn{2}{|c|}{$38.0-71.0$} & \multicolumn{2}{|c|}{$35.0-69.0$} & \multicolumn{2}{|c|}{$34.0-75.0$} & \multirow{3}{*}{$\begin{array}{c}\mathrm{F}= \\
2.566\end{array}$} & \multirow[t]{3}{*}{0.055} \\
\hline Mean \pm SD & & & \multirow{2}{*}{\multicolumn{2}{|c|}{$\frac{56.92 \pm 7.37}{57.0}$}} & \multicolumn{2}{|c|}{$57.44 \pm 7.47$} & \multicolumn{2}{|c|}{$\frac{60.17 \pm 7.70}{62.0}$} & & \\
\hline Median (IQR) & \multicolumn{2}{|c|}{$\begin{array}{c}58.0 \\
(54.0-63.50)\end{array}$} & & & (52. & $3.50)$ & $\begin{array}{r}6 \\
(55 . \\
\end{array}$ & $\begin{array}{l}05.0) \\
65\end{array}$ & & \\
\hline
\end{tabular}

Table (2): General risk factors.

\begin{tabular}{|c|c|c|c|c|c|c|c|c|c|c|}
\hline & \multicolumn{2}{|c|}{$\begin{array}{c}\mathrm{S} \text { (End } \\
\text { inspiratory) } \\
(\mathrm{n}=71)\end{array}$} & \multicolumn{2}{|c|}{$\begin{array}{l}\mathrm{R} \text { (Valsalva } \\
\text { expiratory) } \\
(\mathrm{n}=73)\end{array}$} & \multicolumn{2}{|c|}{$\begin{array}{l}\text { Q (Valsalva- } \\
\text { inspiratory) } \\
(\mathrm{n}=75)\end{array}$} & \multicolumn{2}{|c|}{$\begin{array}{l}\mathrm{P}(\text { End- } \\
\text { expiratory) } \\
(\mathrm{n}=72)\end{array}$} & \multirow[t]{2}{*}{$\begin{array}{c}\text { Test of } \\
\text { sig. }\end{array}$} & \multirow[t]{2}{*}{$\mathrm{p}$} \\
\hline & No. & $\%$ & No. & $\%$ & No. & $\%$ & No. & $\%$ & & \\
\hline \multicolumn{11}{|l|}{ Diabetes mellitus } \\
\hline Negative & 39 & 54.9 & 39 & 53.4 & 41 & 54.7 & 37 & 51.4 & \multirow{2}{*}{$\begin{array}{c}\text { and } \\
\text { and } \\
\end{array}$} & \multirow[t]{2}{*}{0.973} \\
\hline Positive & 32 & 45.1 & 34 & 46.6 & 34 & 45.3 & 35 & 48.6 & & \\
\hline \multicolumn{11}{|l|}{ Hypertension } \\
\hline Negative & 43 & 60.6 & 31 & 42.5 & 38 & 50.7 & 38 & 52.8 & \multirow{3}{*}{ 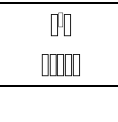 } & \multirow[t]{2}{*}{0.188} \\
\hline Positive & 28 & 39.4 & 42 & 57.5 & 37 & 49.3 & 34 & 47.2 & & \\
\hline Ejection fraction $\%$ & \multicolumn{2}{|c|}{$(\mathrm{n}=70)$} & \multicolumn{2}{|c|}{$(\mathrm{n}=72)$} & \multicolumn{2}{|c|}{$(\mathrm{n}=75)$} & \multicolumn{2}{|c|}{$(\mathrm{n}=70)$} & & \\
\hline Fair $(30-50 \%)$ & 21 & 30.0 & 11 & 15.3 & 14 & 18.7 & 10 & 14.3 & 吅 & \multirow[t]{2}{*}{0.073} \\
\hline Good $>50 \%$ & 49 & 70.0 & 61 & 84.7 & 61 & 81.3 & 60 & 85.7 & 때미 & \\
\hline Hypercholesterolemia & \multicolumn{2}{|c|}{$(\mathrm{n}=70)$} & \multicolumn{2}{|c|}{$(n=72)$} & \multicolumn{2}{|c|}{$(\mathrm{n}=75)$} & \multicolumn{2}{|c|}{$(\mathrm{n}=70)$} & & \\
\hline Negative & 66 & 94.3 & 62 & 86.1 & 67 & 89.3 & 63 & 90.0 & 吅 & \multirow[t]{2}{*}{0.449} \\
\hline Positive & 4 & 5.7 & 10 & 13.9 & 8 & 10.7 & 7 & 10.0 & and & \\
\hline
\end{tabular}

Table (3): Respiratory risk factors

\begin{tabular}{|c|c|c|c|c|c|c|c|c|c|c|}
\hline & \multicolumn{2}{|c|}{$\begin{array}{c}\text { S (End } \\
\text { inspiratory) }\end{array}$} & \multicolumn{2}{|c|}{$\begin{array}{l}\mathrm{R} \text { (Valsalva } \\
\text { expiratory) }\end{array}$} & \multicolumn{2}{|c|}{$\begin{array}{c}\text { Q (Valsalva - } \\
\text { inspiratory) }\end{array}$} & \multicolumn{2}{|c|}{$\begin{array}{c}\mathrm{P}(\text { End- } \\
\text { expiratory) }\end{array}$} & \multirow[t]{2}{*}{$\chi^{2}$} & \multirow[t]{2}{*}{$\mathrm{p}$} \\
\hline & No. & $\%$ & No. & $\%$ & No. & $\%$ & No. & $\%$ & & \\
\hline Smoking & \multicolumn{2}{|c|}{$(\mathrm{n}=70)$} & \multicolumn{2}{|c|}{$(n=71)$} & \multicolumn{2}{|c|}{$(n=75)$} & \multicolumn{2}{|c|}{$(\mathrm{n}=68)$} & \multirow{4}{*}{ 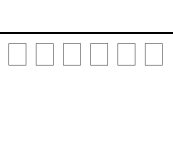 } & \multirow{4}{*}{$0.025^{*}$} \\
\hline Never & 32 & 45.7 & 35 & 49.3 & 33 & 44.0 & 42 & 61.8 & & \\
\hline Ex-smoker & 29 & 41.4 & 32 & 45.1 & 28 & 37.3 & 24 & 35.3 & & \\
\hline Still smoking & 9 & 12.9 & 4 & 5.6 & 14 & 18.7 & 2 & 2.9 & & \\
\hline $\begin{array}{l}\text { Respiratory } \\
\text { disease }\end{array}$ & \multicolumn{2}{|c|}{$(\mathrm{n}=70)$} & \multicolumn{2}{|c|}{$(\mathrm{n}=72)$} & \multicolumn{2}{|c|}{$(\mathrm{n}=75)$} & \multicolumn{2}{|c|}{$(\mathrm{n}=70)$} & & \\
\hline No & 69 & 98.6 & 72 & 100.0 & 74 & 98.7 & 68 & 97.1 & 2.083 & ${ }^{M C} \mathrm{p}=$ \\
\hline Yes & 1 & 1.4 & 0 & 0.0 & 1 & 1.3 & 2 & 2.9 & & 0.560 \\
\hline
\end{tabular}

$\chi^{2}$ : Chi square test, MC: Monte Carlo, $\mathrm{p}$ : $\mathrm{p}$ value for comparing between the studied groups

Site of pleural drain; There were two techniques of insertion of pleural drains at the end of CABG procedure, some surgeons used sub-sternal central mediastino-pleural drain and others preferred to use the lateral intercostal pleural drain. Table (4) show sthe distribution of pleural drain insertion technique among groups. Central mediastino-pleural drains represent about $37.8 \%$ of study cases. 
Table (4): pleural drain site

\begin{tabular}{|c|c|c|c|c|c|c|c|c|c|c|}
\hline & \multicolumn{2}{|c|}{$\begin{array}{c}\mathrm{S} \text { (End } \\
\text { inspiratory) } \\
(\mathrm{n}=71)\end{array}$} & \multicolumn{2}{|c|}{$\begin{array}{l}\mathrm{R} \text { (Valsalva } \\
\text { expiratory) } \\
(\mathrm{n}=73)\end{array}$} & \multicolumn{2}{|c|}{$\begin{array}{c}\text { Q (Valsalva - } \\
\text { inspiratory) } \\
(\mathrm{n}=75)\end{array}$} & \multicolumn{2}{|c|}{$\begin{array}{l}\mathrm{P}(\text { End- } \\
\text { expiratory) } \\
(\mathrm{n}=72)\end{array}$} & \multirow[t]{2}{*}{$\square^{\square}$} & \multirow[t]{2}{*}{$\mathrm{p}$} \\
\hline & No. & $\%$ & No. & $\%$ & No. & $\%$ & No. & $\%$ & & \\
\hline \multicolumn{11}{|l|}{ Pleural drain site } \\
\hline Central Mediastino-pleural & 37 & 52.1 & 27 & 37.0 & 30 & 40.0 & 16 & 22.2 & \multirow[t]{2}{*}{$13.792^{*}$} & \multirow[t]{2}{*}{0.003} \\
\hline Separate Lateral & 34 & 47.9 & 46 & 63.0 & 45 & 60.0 & 56 & 77.8 & & \\
\hline
\end{tabular}

Duration of the pleural drains; Most of the pleural drains in this study $72.5 \%$ were removed within two days post-operatively and the rest were removed after longer duration.

Newly developed pneumothorax (recurrent pneumothorax); it's defined in this study as the pneumothorax that appears in post removal chest X-ray film that wasn't present in the pre removal chest X-ray or increase in the size of the pneumothorax that was present in pre removal chest $\mathrm{X}$-ray. Recurrent pneumothorax occurred in 6 patients $(8.3 \%)$ in group $(\mathrm{P}), 8$ patients $(10.7 \%)$ in group (Q), 9 patients $(12.3 \%)(7$ small pneumothoraces 2 clinical significant pneuomothoraces that reqired re-insertion of intercostal drain) in group (R) and in 5 patients $(7 \%)$ in group (S). All of these pneuomothoraces were small and clinically insignificant except for 2 cases out of the 9 pneumothoraces that occurred in ( $\mathrm{R})$ group. As shown in Tables (5), (6) and diagram (1).

Re-arrangement of the data of all the study cases according to the distribution of recurrent pneuomothorax cases between different methods of pleural drain insertion in (CABG) and its duration showed no statistical significance that can link recurrent pneuomothorax to either the site or duration of the pleural drain as shown in Tables (7),(8) an Diagrams (2),(3).

Table (5): Rate and distribution of newly developed pneumothorax

\begin{tabular}{|c|c|c|c|c|c|c|c|c|c|c|}
\hline & \multicolumn{2}{|c|}{$\begin{array}{c}\mathrm{S} \text { (End } \\
\text { inspiratory) } \\
(\mathrm{n}=71)\end{array}$} & \multicolumn{2}{|c|}{$\begin{array}{c}\text { R (Valsalva } \\
\text { expiratory) } \\
(\mathrm{n}=73)\end{array}$} & \multicolumn{2}{|c|}{$\begin{array}{c}\text { Q (Valsalva - } \\
\text { inspiratory) } \\
(\mathrm{n}=75)\end{array}$} & \multicolumn{2}{|c|}{$\begin{array}{c}\mathrm{P}(\text { End- } \\
\text { expiratory) } \\
(\mathrm{n}=72)\end{array}$} & \multirow[t]{2}{*}{$\chi^{2}$} & \multirow[t]{2}{*}{$\mathrm{p}$} \\
\hline & No. & $\%$ & No. & $\%$ & No. & $\%$ & No. & $\%$ & & \\
\hline \multicolumn{11}{|c|}{ New Pneumothorax } \\
\hline Negative & 66 & 93.0 & 64 & 87.7 & 67 & 89.3 & 66 & 91.7 & \multirow[t]{2}{*}{ पाता } & \multirow[t]{2}{*}{0.708} \\
\hline Positive & 5 & 7.0 & 9 & 12.3 & 8 & 10.7 & 6 & 8.3 & & \\
\hline
\end{tabular}

$\chi^{2}$ : Chi square test $p: p$ value for comparing between the studied groups

Table (6): Clinically significant pneumothorax.

\begin{tabular}{|c|c|c|c|c|c|c|c|c|}
\hline & \multicolumn{2}{|c|}{$\begin{array}{c}\text { S (End } \\
\text { inspiratory) } \\
(\mathrm{n}=71)\end{array}$} & \multicolumn{2}{c|}{$\begin{array}{c}\text { R (Valsalva } \\
\text { expiratory) } \\
(\mathrm{n}=73)\end{array}$} & \multicolumn{2}{c|}{$\begin{array}{c}\text { Q (Valsalva - } \\
\text { inspiratory) } \\
(\mathrm{n}=75)\end{array}$} & \multicolumn{2}{c|}{$\begin{array}{c}\text { P (End- } \\
\text { expiratory) } \\
\text { (n=72) }\end{array}$} \\
\hline & No. & $\%$ & No. & $\%$ & No. & $\%$ & No. & $\%$ \\
\hline $\begin{array}{c}\text { New Pneumothorax } \\
\text { Positive cases }\end{array}$ & 5 & 7.0 & 9 & 12.3 & 8 & 10.7 & 6 & 8.3 \\
\hline $\begin{array}{c}\text { Clinical } \\
\text { insignificant }\end{array}$ & 5 & 7.0 & 7 & 9.6 & 8 & 10.7 & 6 & 8.3 \\
\hline Clinical significant & 0 & 0 & 2 & 2.74 & 0 & 0 & 0 & 0 \\
\hline
\end{tabular}




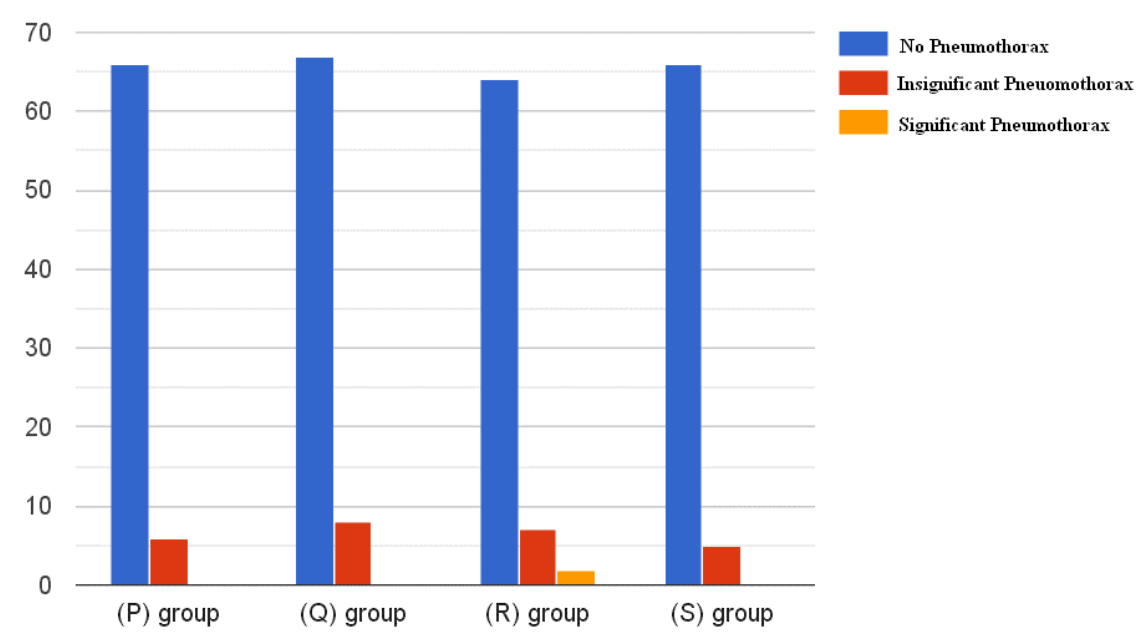

Diagram (1): Occurrence of Pneumothorax after left pleural drain removal in study groups.

Table (7): Relationship between recurrent pneumothorax and the duration after which pleural drain is removed.

\begin{tabular}{|c|c|c|c|c|}
\hline & $\begin{array}{c}\leq 2 \text { days } \\
(\mathrm{n}=211)\end{array}$ & $\begin{array}{c}>2 \text { days } \\
(\mathrm{n}=80)\end{array}$ & $\chi^{2}$ & $\mathrm{P}$ \\
\hline Total number of cases(n) & 211 & 80 & & \\
\hline Cases with positive finding & 23 & 5 & 1.443 & 0.230 \\
\hline Critical cases & 2 & 0 & 0.764 & ${ }^{\mathrm{FE}} \mathrm{p}=1.000$ \\
\hline
\end{tabular}

$\chi^{2}$ : Chi square test FE: Fisher Exact p: $p$ value for comparing between the studied groups

Table (8): Relationship between recurrent pneumothorax and the site of the pleural drain.

\begin{tabular}{|c|c|c|c|c|}
\hline & $\begin{array}{c}\text { Central tube } \\
(\mathrm{n}=110)\end{array}$ & $\begin{array}{c}\text { Lateral tube } \\
(\mathrm{n}=181)\end{array}$ & $\chi^{2}$ & $\mathrm{p}$ \\
\hline Total number of cases(n) & 110 & 181 & & \\
\hline Cases with positive finding & $8(7.3 \%)$ & $20(11 \%)$ & 1.122 & 0.289 \\
\hline Critical cases & $0(0.0 \%)$ & $2(1.1 \%)$ & 1.224 & ${ }^{\mathrm{FE}} \mathrm{p}=0.528$ \\
\hline
\end{tabular}

$\chi^{2}$ : Chi square test FE: Fisher Exact p: $p$ value for comparing between the studied groups

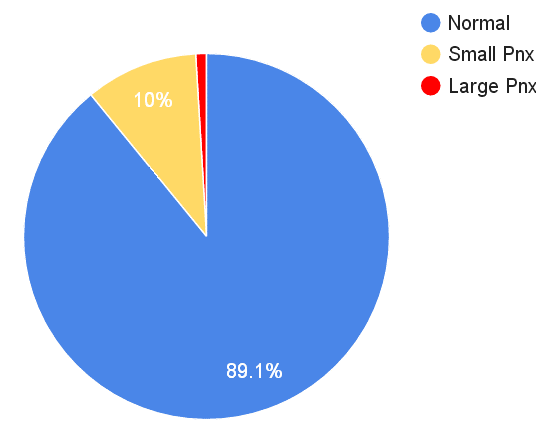

Drains removed after $\leq 2$ days

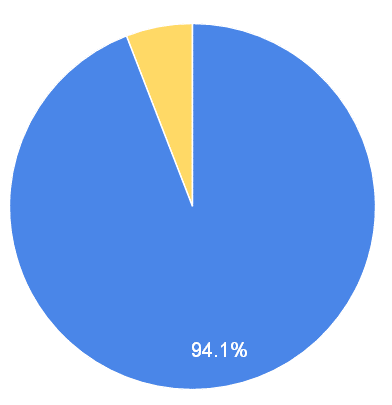

Drains removed after $>2$ days

Diagram (2): Relationship between duration of left pleural drains and recurrent pneumothorax. 

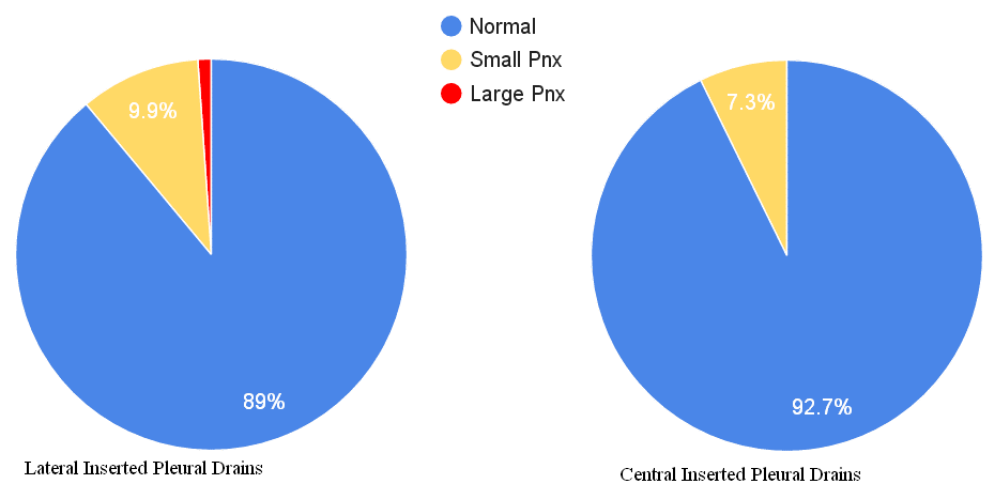

Diagram (3): Relationship between site of insertion of left pleural drains and recurrent pneumothorax.

\section{DISCUSSION:}

Tube Thoracostomy is widely used as a main method of draining the pleural space for a variety of conditions especially traumatic pneumothorax or haemothorax and it is still the standard main method of postoperative pleural drainage. recurrent pneumothorax has been the most common complication after ICT removal.

A number of studies have been conducted to detect the effect of respiratory phase and its relation to the occurrence of recurrent pneumothorax.

Few studies have been conducted aiming to determine the best phase of respiratory cycle during which recurrent pneumothorax is less likely to occur.

Bell et al ${ }^{(6)}$, conducted their study on 69 trauma patients who had 102 intercostal tubes and randomized them according to respiratory phases into 2 groups, endinspiratory group which had 52 patients and end-expiratory group that had 50 patients. both of phases were done during Valsalva maneuver. recurrent pneumothorax occurred in 4 patients $(8 \%)$ in end-inspiratory group and 2 of them required re-insertion of intercostal tube, and in end-expiratory group recurrent pneumothorax occurred in 3 patients $(6 \%)$ and only one of them required re-insertion of intercostal tube. they concluded that it's safe to remove intercostal tube in any of both phases.

Cerfolio and colleagues ${ }^{(7)}$ Published a study in 2013 that was conducted on 342 patients I who had lung resection surgeries. Patients were randomized into 2 groups according to respiratory phases, 179 patients in end-inspiratory group and 163 patients in end-expiratory group. patients performed Valsalva maneuver during the adapted respiratory phase. Recurrent pneumothorax occurred in 63 patients in end-inspiratory group $(35 \%)$ and 5 of them $(3 \%)$ required intercostal tube reinsertion. in endexpiratory group recurrent pneumothorax occurred in 34 patients $(20 \%)$ and 2 of them (1\%) needed re-insertion of intercostal drain. They generally favored removal of intercostal tube while the patient is performing Valsalva maneuver at the end of expiration but they also concluded that clinically significant recurrent pneumothorax that requires surgical intervention has no statistical relation to either of their study groups.

Thitivaraporn et $\mathrm{al}^{(8)}$, published preliminary results of their study that was conducted on 48 trauma patients who had intercostal tubes. They were randomized into 
4 groups as the following: 13 patients in group A who performed classic Valsalva maneuver at the end of inspiration, 12 patients in group B who performed classic Valsalva maneuver at the end of expiration, 12 patients in group $\mathrm{C}$ who performed Valsalva maneuver at the end of inspiration aided by party balloon and 11 patients in group D who performed Valsalva maneuver at the end of expiration aided by party balloon. recurrent pneumothorax has occurred in 2 patients in group A (15\%) and in 2 patients in group B $(17 \%)$. it didn't occur in group $\mathrm{C}$ or $\mathrm{D}$. only one of the patients who had recurrent pneumothorax required intercostal tube re-insertion and this patient was in group B.

In our study we have conducted it on left side pleural drains in patients who had coronary artery bypass grafting surgery in whom left internal thoracic artery was harvested and left pleura was entered. this means that the lung should be intact, unless injured by wires used in sternal closure or by ventilator related barotrauma or central venous catheter insertion, which is less common on left side as it's inserted during anesthesia on right side. When the left pleura is entered, it will be connected to the mediastinum and pleural drain is inserted for fear of any accumulation of fluid or blood in the pleural space instead of getting drained by mediastinal drain.

We have allocated 291 patients according to the respiratory phase they should adapt into 4 different groups as follows:72 patients in group (P) endexpiratory 6 patients of the $(8.3 \%)$ developed non-significant recurrent pneumothorax, 75 patients in group (Q) valsalva-inspiratory and 8 of them $(10.7 \%)$ developed non-significant recurrent pneumothorax., 73 patients in group (R): valsalva-expiratory group. 9 of them (12.3\%) developed recurrent pneumothorax which was insignificant in 7 cases $(9.6 \%)$ and was significant in 2 cases $(2.74 \%)$ and required re-insertion of intercostal tube, 71 patients in group (S): end- expiratory group and 5 of them (7\%) developed nonsignificant recurrent pneumothorax.

In order to reach the number of 291 patients we have removed the pleural drains of more than 400 patients of whom only 300 patients could be included in this study as the rest of patients were excluded for different factors including: apparent transition from the requested respiratory phase to another phase during removal or post removal chest X-ray couldn't be done within the proper time period targeted in this study. Further results of 9 patients from the 300 were excluded due to bad quality post removal chest $\mathrm{X}$-ray films that couldn't confirm or exclude presence of recurrent pneumothorax.

Phase of respiratory cycle, that the patient is asked to adapt, is a patient dependent or patient related factor i.e. subjective factor. during our study many patients haven't apparently stick to the instructed respiratory phase. some of them yelled or talked during pleural drain removal and respiratory movements during removal were observed in others. unapparent transition from one respiratory phase to another couldn't be discovered during conducting of this study. this may explain why Valsalva expiratory group ( $\mathrm{R}$ group) in this study, against initial expectations, has the highest rate of recurrence among study groups. adapting end-expiratory phase while performing Valsalva during pleural drain removal has been observed to be the most difficult phase in this study for patients. It may be attributed to the pain of sternotomy procedure which makes it difficult to adapt a respiratory phase while performing Valsalva-maneuver, especially in expiratory phase. which will lead to transition from one respiratory phase to another either this transition is apparent for the observer or not. when unable to stay in Valsalva expiratory phase, patient usually inhales, which results 
in drop in intra-pleural pressure allowing some atmospheric air to enter the pleura during drain removal. which will usually cause non-significant recurrent pneumothorax.

Recurrent pneumothorax occurred in 28 patients of this study $(9.62 \%)$ and it was clinically and radiologically insignificant in 26 of them $(8.93 \%)$ and only 2 cases $(0.68 \%)$ showed a clinical and radiological significance that required re-insertion of intercostal tube. The rate of recurrent pneumothorax in our study comes in line with previous studies in which rate of recurrent pneumothorax ranged from $2.4 \%$ to $28.3 \%$. but we have a lesser rate of need to intercostal tube re-insertion when compared with previous studies in which the rate ranged from $1.2 \%$ to $6.25 \%$. this may be attributed to the selection of patients in our study who have s better lung condition in comparison to trauma patients who have been the subject of previous studies.

One of the latter 2 cases, in whom recurrent pneumothorax was significant, had an un-planned chest X-ray after one hour of drains removal and there was a nonsignificant recurrent pneumothorax but later on in $24 \mathrm{hrs}$ post removal routine chest X-ray there was a significant pneumothorax that was proved by clinical evaluation of the patient. examination of the thoracostomy wound upon routine dressing showed good closure of the wound. this suggests that the significant recurrent pneumothorax that occurred in this case can't be attributed to drain removal technique.

Statistical analysis of these results revealed no statistical significance of respiratory phase in relation to recurrent pneumothorax and We can say it's safe remove the pleural drain while the patient is holding his/her breath in any of respiratory phases.

\section{Conclusion;}

After statistical analysis of the results of this study we can say that in post CABG surgery patients, the respiratory phase during which the pleural drain is removed has no role in occurrence of recurrent pneumothorax, when it's performed by a well-trained physician and it's not necessary to ask the patient to adapt the painful ValsalvaManeuver during the removal procedure.

Also, we can conclude that the site of the pleural drain or the duration after which pleural drain is removed have no roles in occurrence of recurrent pneumothorax.

After considering the results of this study and the results of similar studies that aimed to detect the effect of respiratory phase during pleural drain removal on the rate of occurrence of recurrent pneumothorax, We can say that under normal circumstances where the pleural drain is removed in proper timing by a welltrained physician while the patient is holding his/her with proper closure of thoracostomy wound, the recurrent pneumothorax can't be attributed to the removal technique regarding the respiratory phase which the patient is asked to adapt during the removal procedure.

\section{REFERENCES:}

1. Ginwalla R, Faraday N, Whitman G: Postoperative Management of the Cardiac Surgical Patient. In: Yuh DD, Vricella LA, Yang SC, Doty JR (editors): Johns Hopkins Textbook Of Cardiothoracic Surgery. $2^{\text {nd }} e$, McGraw-Hill Education/Medical (USA); 2014. 26:371.

2. Khalpey ZI, Schmitto JD, Rawn JD: Postoperative Care of Cardiac Surgery Patients. In: Cohn LH(editor): Cardiac surgery in the adult. $4^{\text {th }}$ e, McGraw-Hill Education / Medical (USA); 2011. 16:381.

3. Bojar RM: Mediastinal Bleeding. In: Bojar RM (editor): Manual of Perioperative Care 


\section{Ahmed Anwar Elnory, et al.,}

in Adult Cardiac Surgery. $5^{\text {th }}$, WileyBlackwell (USA); 2011.9:356.

4. Mirmohammad-Sadeghi M, Etesampour A, Gharipour M, Shariat Z, Nilforoush P, Saeidi M, Mackie M, MirmohammadSadeghi F. Early chest tube removal after coronary artery bypasses graft surgery. $\mathrm{N}$ Am J Med Sci. 2009;1(7):333-7

5. Kwiatt M, Tarbox A, Seamon MJ, et al. Thoracostomy tubes: a comprehensive review of complications and related topics. Int J Crit Illn Inj Sci. 2014;4:143-55.

6. Bell RL, Ovadia P, Abdullah F, Spector S, Rabinovici R. Chest tube removal: End- inspiration or end-expiration?. J Trauma. 2001;50:674-7.

7. Cerfolio RJ, Bryant AS, Skylizard L, Minnich DJ. Optimal technique for the removal of chest tubes after pulmonary resection. J Thorac Cardiovasc Surg. 2013; 145:1535-9.

8. Thitivaraporn $P$, Narueponjirakul $N$, Samorn P, Prichayudh S, Sriussadaporn S, Pak-Art R, Sriussadaporn S, Kritayakirana $\mathrm{K}$. Randomized controlled trial of chest tube removal aided by a party balloon. Asian Cardiovasc. Thorac Ann. 2017; 25(78):522-527.

\section{إزالة الأنابيب الصدرية فى المرضى الذين خضعوا لجراحة تحويل مسار الدم بالثرايين التاجية: هل تؤثر الأطوار المختلفة للتنفس أثناء الإزالة؟

$$
\text { أحمد النورى ، هانى حسن السيد ، مصطفى جمال البربرى ، شيماء صلاح ، أحمد النادى أحمد عبدالعال }
$$

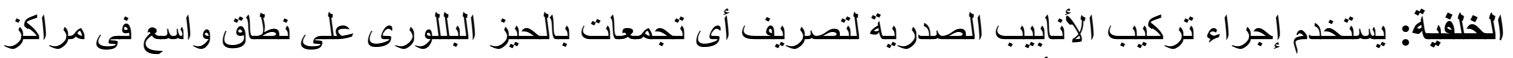

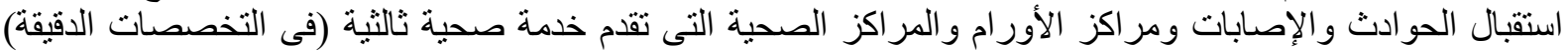

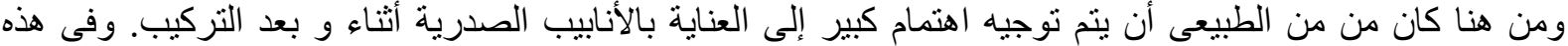
الدراسة تهدف إلى التعرف عنى الطور التنفسى الأنسب لإز النة الأنابيب الصدرية.

$$
\text { الهدف: فى هذه الدر اسة تهدف إلى التعرف على الطور التنفسى الأنسب لإز الة الأنابيب الصدرية. }
$$

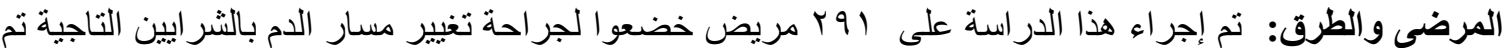

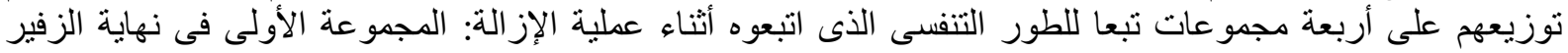

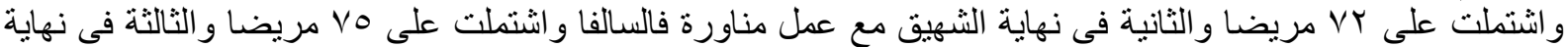

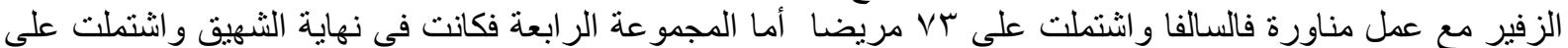

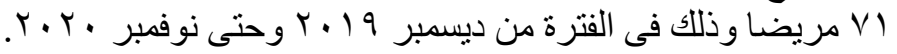

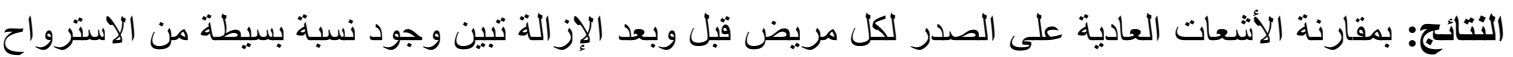

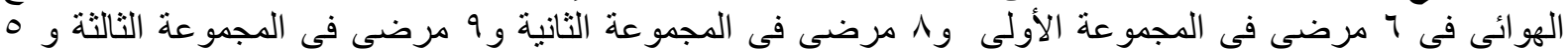

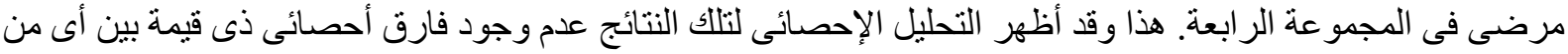
تللك المجمو عات. الاستتناج: يمكن إز الة الأنابيب الصدرية بشكل آمن فى أى من أطوار التنفس إذا تم ذلك بو اسطة طبيب مدرب. 